CLINICAL STUDY

\title{
Bone loss after childhood acute lymphoblastic leukaemia: an observational study with and without GH therapy
}

\author{
Cecilia Follin ${ }^{1}$, Katarina Link ${ }^{1}$, Thomas Wiebe ${ }^{2}$, Christian Moëll ${ }^{2}$, Jonas Björk ${ }^{3}$ and E M Erfurth ${ }^{1}$ \\ ${ }^{1}$ Department of Endocrinology, ${ }^{2}$ Department of Paediatrics and ${ }^{3}$ Competence Center for Clinical Research, Skåne University Hospital, \\ SE-221 85 Lund, Sweden \\ (Correspondence should be addressed to C Follin; Email: cecilia.follin@med.lu.se)
}

\begin{abstract}
Objective: Bone mineral density (BMD) in survivors of acute lymphoblastic leukaemia (ALL) seems to vary with time, type of treatments and GH status. We aimed to evaluate BMD in ALL patients with GH deficiency (GHD), with and without GH therapy.

Design: Case-control study.

Methods: We examined 44 (21 women) GHD patients (median 25 years) treated with cranial radiotherapy (18-24 Gy) and chemotherapy and matched population controls for BMD with dualenergy X-ray absorptiometry. For 5 and 8 years, two subgroups with $(0.5 \mathrm{mg} / \mathrm{day})(n=16)$ and without GH therapy $(n=13)$ and matched controls were followed respectively.

Results: At baseline, no significant differences in BMD or Z-scores at femoral neck and L2-L4 were recorded (all $P>0.3$ ). After another 8 years with GHD, the Z-scores at femoral neck had significantly decreased compared with baseline $(0.0$ to $-0.5 ; P<0.03)$ and became lower at the femoral neck $(P=0.05)$, and at L2-L4 $(P<0.03)$, compared with controls. After 5 years of GH therapy, only female ALL patients had a significantly lower femoral neck Z-scores $(P=0.03)$. The female ALL patients reached an IGF1 level of -0.7 S.D. and male patients reached the level of +0.05 S.D.

Conclusions: On average, 25 years after diagnosis, GH-deficient ALL patients experienced a significant decrease in Z-scores at femoral neck, and if Z-scores continue to decrease, there could be a premature risk for osteoporosis. GH therapy was not shown to have a clear beneficial effect on BMD. Whether higher GH doses, particularly in women, will improve Z-scores needs further investigation.
\end{abstract}

European Journal of Endocrinology 164 695-703

\section{Introduction}

Acute lymphoblastic leukaemia (ALL) is the most common paediatric malignancy (1) and its treatment includes many known risk factors for low bone mineral density (BMD). High doses of glucocorticosteroids and methotrexate (MTX), included in nearly all ALL treatment regimes, can at least temporarily affect bone formation $(2,3)$. Furthermore, boys with radiation to the testes need adequate testosterone supplementation, and patients treated with cranial radiotherapy (CRT) are at risk, particularly for GH deficiency $(\mathrm{GHD})(4,5)$. Adults with child onset (CO) GHD, due to hypothalamicpituitary disease, have shown reduced BMD and bone mineral content (BMC) (6), and discontinuation of GH therapy before attainment of peak bone mass (PBM) is suggested as the main cause of low bone mass (7). After GH replacement, beneficial effect on BMD and BMC $(8,9)$, together with increased markers of bone turnover, has been shown $(8,9)$.

As patients with CO GHD are shorter (5), their bones have smaller width and will also be thinner, i.e. volume corrections, using bone mineral apparent density (BMAD), are therefore preferable (10). There are conflicting results regarding long-term BMD in former ALL patient where six studies have shown low BMD, 4-24 years after 18-30 Gy of CRT (11-16) and two studies showed normal BMD, 4-20 years after 18-24 Gy $(17,18)$. In these studies, GH status has only been taken into account in subgroups of patients (12, 14-17) and often with GH tests not always optimal to unmask radiation-induced GHD $(13,16)$. In a recent large study, normal BMD was recorded 10 years after diagnosis, with the exception of low BMD in a subgroup of patients treated with high doses of MTX (18). Thus, BMD status is not definitely settled in adult ALL patients and seems to vary with time following treatment, type of treatment and with GH status. Furthermore, properly matched controls have previously not been included and have neither physical activity nor calcium intake or serum levels of thyroid and sex steroids been carefully addressed.

One aim of this study was to evaluate BMD, using dual-energy X-ray absorptiometry (DXA) and with volume correction using BMAD, and markers of bone 
turn over in a representative cohort of adults with $\mathrm{CO}$ GHD, treated with CRT and chemotherapy for ALL. Another aim was to evaluate the effect of 5 years of GH therapy on BMD in a subgroup of GH-deficient ALL patients and to compare them with an untreated GH-deficient ALL group after 8 years. Comparisons were also made with matched population controls at baseline and to the same population controls after 5 and 8 years of follow-up.

\section{Subjects and methods}

\section{Patients}

A consecutive study of 58 surviving patients treated for childhood ALL with chemotherapy and CRT with a median dose of 24 Gy (18-24) during 1971-1992 at the Children's Hospital Lund, Sweden, and $\geq 18$ years of age were invited to participate in a study in the year 2000 (5). In the period 1971-1981, all patients diagnosed with ALL received CRT. In the latter period (1982-1992), children belonging to the lower risk groups received no CRT. All patients had received chemotherapy according to the common protocols of the Nordic countries and of the Swedish Child Leukemia Group, details presented in Table 1, and all patients were in first remission. Excluded and included patients are shown in Fig. 1 and Table 1. Of all the patients, 18 (eight women) were offered GH therapy and 15 patients completed the present 5-year study. The GH dose
(Humatrope, Eli Lilly and Company) of $0.5 \mathrm{mg} /$ day $(0.2-0.8)$ for women and men, was given by s.c. injections. The $\mathrm{GH}$ dose was titrated against the response of serum insulin-like growth factor (IGF1), aiming at a \pm 0 IGF1 level. Another subgroup of 13 patients (four women) was not offered GH therapy but had regular contact with a doctor or nurse during 8 years of follow-up. The main reasons to be included in the GH-therapy group were as follows: willing to accept GH therapy, living close to the hospital and able to participate in a long-term study. The remaining 16 patients were excluded due to reasons shown in Fig. 1.

A total of four patients had previously received $\mathrm{GH}$ treatment in childhood, but not for at least 5 years. All females had spontaneous and regular menstrual cycles except for one patient with primary amenorrhoea and five patients were using oestrogen contraceptives. Of the 12 males who had received radiation to the testes, ten were properly substituted with testosterone as injections $(n=7)$, tablets $(n=1)$ or patches $(n=2)$. Of the 12 patients subjected to testis radiation, two had no androgen substitution: one had not been properly irradiated due to an undescended testis and had normal testosterone levels and the other was not sufficiently substituted; three men and two women were smokers.

\section{Control groups}

Each patient was matched with a control subject $(n=44)$ similar in age, sex, residence (rural/nonrural) and smoking habits who was randomly selected

Table 1 Patients' baseline characteristics, medical history and GH status in 44 former ALL patients with and without GH treatment. Data are presented as median and range (min-max).

\begin{tabular}{|c|c|c|c|}
\hline & $\begin{array}{l}5 \text { years of } \mathbf{G H} \\
\text { therapy }(n=15)\end{array}$ & $\begin{array}{l}8 \text { years of GHD } \\
(n=13)\end{array}$ & $\begin{array}{l}\text { Excluded patients } \\
(n=16)\end{array}$ \\
\hline Men/women ( $n)$ & $7 / 8$ & $9 / 4$ & $7 / 9$ \\
\hline Height $(\mathrm{cm})$ & $161(149-181)$ & $170(148-186)$ & $162(150-192)$ \\
\hline Weight $(\mathrm{kg})$ & $66(44-98)$ & $79(53-121)$ & $74(50-127)$ \\
\hline Age at diagnosis (years) & $3.9(1-17)$ & $4.2(2-9)$ & $6.3(2-13)$ \\
\hline Years since CRT (years) & $21(8-27)$ & $19(9-27)$ & $19(9-27)$ \\
\hline Target dose CRT (Gy) & $24(18-24)$ & $24(24-25)$ & $24(18-30)$ \\
\hline Anthracycline dose $\left(\mathrm{mg} / \mathrm{m}^{2}\right)$ & $120(80-540)$ & $120(40-540)$ & $120(60-540)$ \\
\hline MTX dose i.t. $\left(\mathrm{mg} / \mathrm{m}^{2}\right)$ & $60(12-144)$ & $72(12-204)$ & $110(60-324)$ \\
\hline MTX dose i.v. $\left(\mathrm{mg} / \mathrm{m}^{2}\right)$ & $3000(3000-4000)$ & $1763(30-4000)$ & $3000(3000-4000)$ \\
\hline MTX dose p.o. $\left(\mathrm{mg} / \mathrm{m}^{2}\right)$ & $2672(533-4200)$ & $2723(1097-3900)$ & 2687 (893-3600) \\
\hline Prednisolone dose $\left(\mathrm{mg} / \mathrm{m}^{2}\right)$ & 2508 (1600-6682) & $2410(1540-6573)$ & 2514 (1610-6432) \\
\hline Decadron dose $\left(\mathrm{mg} / \mathrm{m}^{2}\right)$ & $370(296-390)$ & $325(200-400)$ & $340(300-400)$ \\
\hline Standard/intermediate/high-risk group $(n)$ & $11 / 0 / 5$ & $10 / 0 / 3$ & $8 / 1 / 6$ \\
\hline Testes radiation ( $n$ )/target dose (Gy) & $4 / 24$ & $5 / 24$ & $3 / 24$ \\
\hline Peak GH during ITT $(\mu \mathrm{g} / \mathrm{l})$ & $0.4(0.4-2.4)$ & $0.2\left(0.04-4.6^{\mathrm{a}}\right)$ & $0.4(0.2-3.8)$ \\
\hline IGF1 $(\mu \mathrm{g} / \mathrm{I})$ & $124(75-264)$ & $142(81-329)$ & $134(78-256)$ \\
\hline $\mathrm{GH}$ during childhood & 1 & 2 & 1 \\
\hline Oral contraception & 2 & 1 & 2 \\
\hline BMD Z-score femoral neck & $-0.2(-1.6$ to 1.5$)$ & $0.0(-1.5$ to 1.3$)$ & $0.4(-2.0$ to 1.4$)$ \\
\hline BMD Z-score L2-L4 & $-0.4(-1.6$ to 1.5$)$ & $-0.2(-1.4$ to 2.1$)$ & $-0.3(-2.7$ to 2.0$)$ \\
\hline
\end{tabular}

CRT, cranial radiotherapy; MTX, methotrexate; i.t., intrathecally; p.o., per os; ITT, insulin tolerance test; 1.

${ }^{a}$ One patient responded with $4.6 \mu \mathrm{g} / \mathrm{l}$ but had $<1$ during $\mathrm{GHRH}-$ arginine test and IGF1 - 3.0 s.D. 


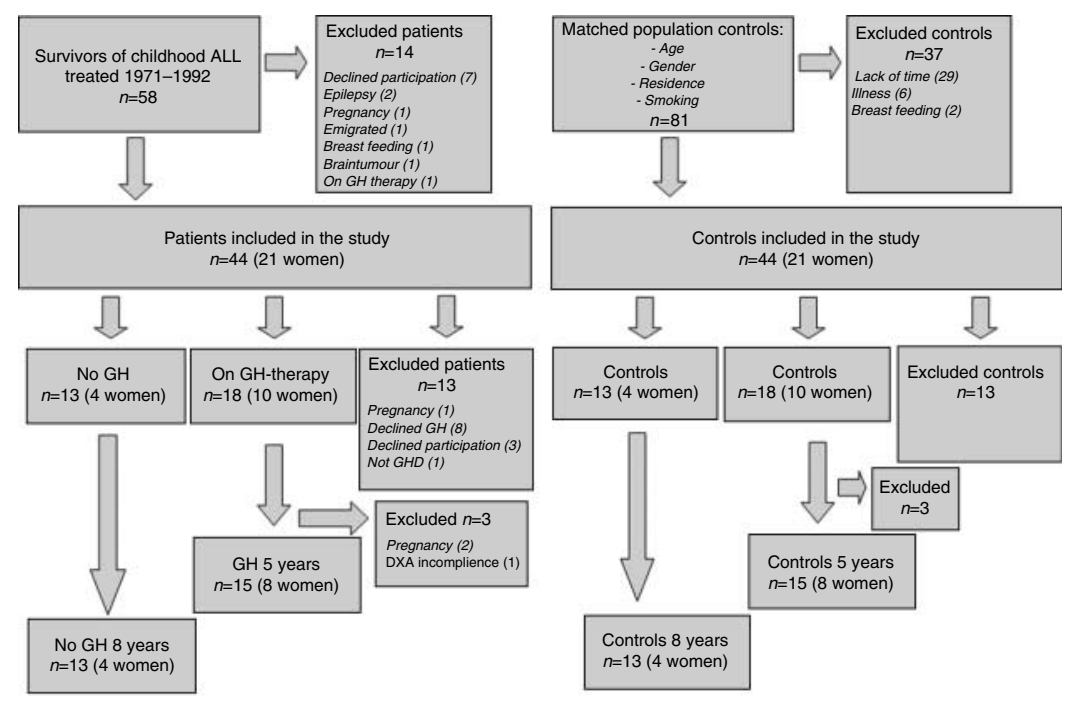

Figure 1 Flow chart of excluded and included former ALL patients and matched population controls. ALL, acute lymphoblastic leukaemia; GHD, GH deficiency. from a computerised population register described in detail elsewhere (5) and in Fig. 1.

All baseline investigations, including DXA and physical activity in the patients and in the controls, were repeated after 5 and 8 years respectively.

All participants gave written informed consent and the study was approved by the Ethic's Committee of Lund University.

\section{BMC, BMD, BMAD and anthropometric measurements}

BMC and BMD of the femoral neck, lumbar spine 2-4 (L2-L4) and Z-scores of femoral neck and L2-L4, standardised to sex, age, weight and race/ethnicity, and body composition, i.e. fat mass and lean mass, were assessed using two DXA machines as one broke during study (Lunar Expert XL (LEXL) and Lunar Prodigy (LP), Lunar Co., Madison, WI, USA). Both the machines were calibrated with the same phantom. For BMD, the coefficient of variation $(\mathrm{CV})$ was 0.6 and $0.2 \%$ respectively, for the LEXL and LP; the CV was $0.7 \%$ between machines. All investigations in both patients and controls at baseline were performed with Lunar Expert and at 5 and 8 years for both patients and controls were performed with LP. The official position of the International Society for Clinical Densitometry states that the WHO classifications (T-scores) for osteoporosis and osteopenia are not applicable to premenopausal women or men and recommended instead that Z-scores be used (19). Body mass index (BMI) was defined as body weight $(\mathrm{kg})$ divided by the square of height $(\mathrm{m})$. BMAD was applied and the following formulas for volume corrections were used: for the femoral neck, $\mathrm{BMAD}=\mathrm{BMC} \div$ area and for the spine; $\mathrm{BMAD}=\mathrm{BMC} \div \operatorname{area}^{3 / 2}(10)$.

\section{History of fractures, present calcium intake and physical exercise}

All subjects were interviewed regarding the number of previous fractures and present calcium intake. The degree of physical exercise during working time and spare time was assessed by self-rating questionnaire in which patients and controls classified their physical activity according to a four-grade scale: grade 1 , sedentary lifestyle, e.g. reading and watching television; grade 2, moderate exercise, e.g. bicycling and working in the garden for at least $4 \mathrm{~h}$ a week; grade 3 , regular exercise, e.g. swimming or playing tennis 2 or $3 \mathrm{~h}$ a week; grade 4, hard exercise, e.g. running, skipping or swimming several times per week (20).

\section{Hormone assays, test procedures for GH secretion and markers of bone turnover}

Details of assay procedures for serum levels of IGF1 and testosterone and plasma levels of TSH, free thyroxine $\left(\mathrm{T}_{4}\right)$, free tri-iodothyronine $\left(\mathrm{T}_{3}\right)$ and oestradiol $\left(\mathrm{E}_{2}\right)$ have been presented elsewhere (5). All patients and 44 controls underwent a GHRH-arginine test (21), and 39 patients were also investigated with an insulin tolerance test (ITT). Details of test procedures are shown elsewhere (5). GHD was defined as $<3 \mu \mathrm{g} / \mathrm{l}$ to an ITT or $<9 \mu \mathrm{g} / \mathrm{l}$ to the GHRH-arginine test and with a cut-off point of $11.5 \mu \mathrm{g} / \mathrm{l}$ if BMI $<25 \mathrm{~kg} / \mathrm{m}^{2}, 8.0 \mu \mathrm{g} / \mathrm{l}$ if BMI $>25 \mathrm{~kg} / \mathrm{m}^{2}$ and $<30 \mathrm{~kg} / \mathrm{m}^{2}$ and $4.2 \mu \mathrm{g} / \mathrm{l}$ if BMI $>30 \mathrm{~kg} / \mathrm{m}^{2}$ for this latter test $(22)$. The ITT result determined the GHD classification when the GH response to the GHRH-arginine test was $>9 \mu \mathrm{g} / \mathrm{l}$ (5). All patients in the GH-treated group and all but one in the non-GH-treated group failed the ITT $(\mathrm{GH}=4.6 \mu \mathrm{g} / \mathrm{l})$. This patient had a $\mathrm{GH}$ response of $1 \mu \mathrm{g} / \mathrm{l}$ during the GHRH-arginine test together with an 
IGF1 of -3.0 SDS, at re-testing 7 years after baseline. Serum levels of crossLaps and osteocalcin were analysed with an immunometric method (Elecsys 2010). The detection level for serum crossLaps was $10 \mathrm{ng} / \mathrm{l}$ and the $\mathrm{CV}$ total was $8.3 \%$ at a level of $350 \mathrm{ng} / \mathrm{l}$ and $5.2 \%$ at a level of $3000 \mathrm{ng} / \mathrm{l}$. The detection level for serum osteocalcin was $0.5 \mu \mathrm{g} / \mathrm{l}$, and the CV total was $3.3 \%$ at a level of $20 \mu \mathrm{g} / \mathrm{l}$ and $3.4 \%$ at a level of $200 \mu \mathrm{g} / \mathrm{l}$.

\section{Statistical analysis}

Data are presented as median and range (min-max). Differences between 44 patients and 44 matched population controls, before and after 5 years of $\mathrm{GH}$ treatment and before and after 8 years without, were compared using Wilcoxon's signed rank test for matched pairs. Bivariate correlations were assessed using the Spearman rank correlation coefficient. A $P$ value $<0.05$ was regarded as statistically significant.

We used the SPSS version 15.0 (SPSS Inc., Chicago, IL, USA) for the statistical analysis.

\section{Results}

Anthropometric and hormone assessments in 44 patients in comparison with matched controls at baseline

Height was significantly reduced by $13 \mathrm{~cm}$ ((s.D. -1.25 $(-2.0$ to 0.49$))$ in the male patients and by $9 \mathrm{~cm}(($ s.D. $-1.6(-2.0$ to 1.1$))$ in the female patients (Table 2). BMI and fat mass (FM) were significantly increased in ALL women. Lean mass (LM) was significantly decreased in both genders (Table 2).

Serum levels of IGF1 were significantly lower in both genders, -1.6 S.D. in ALL women and -1.25 S.D. in ALL men. The serum TSH levels were without significant differences between ALL women and men in comparison to controls (1.9 vs 2.0 and 2.1 vs $1.9 \mathrm{mU} / \mathrm{l}$ respectively; >0.3). Serum-free $\mathrm{T}_{4}$ was significantly higher, but in the normal range in the ALL women, compared with controls (14 vs $12 \mathrm{pmol} / \mathrm{l}$, $P=0.04)$, but without difference in ALL men (14 vs $14 \mathrm{pmol} / \mathrm{l}, \quad P=>0.3)$. There were no significant differences in free $T_{3}$ levels in ALL women or men compared with controls (both $P>0.3$ ). Testosterone levels in men (15.5 vs $17.6 \mathrm{nmol} / \mathrm{l})$ and $E_{2}$ levels in women (198 vs $193 \mathrm{pmol} / \mathrm{l})$ were without significant difference compared with controls (both $P>0.3$ ).

\section{BMAD, BMD and markers of bone turnover in 44 patients in comparison with 44 matched controls at baseline}

No significant differences in BMAD, BMD or in Z-scores at femoral neck or L2-L4 were recorded in former ALL patients of both genders (Table 2). When the male

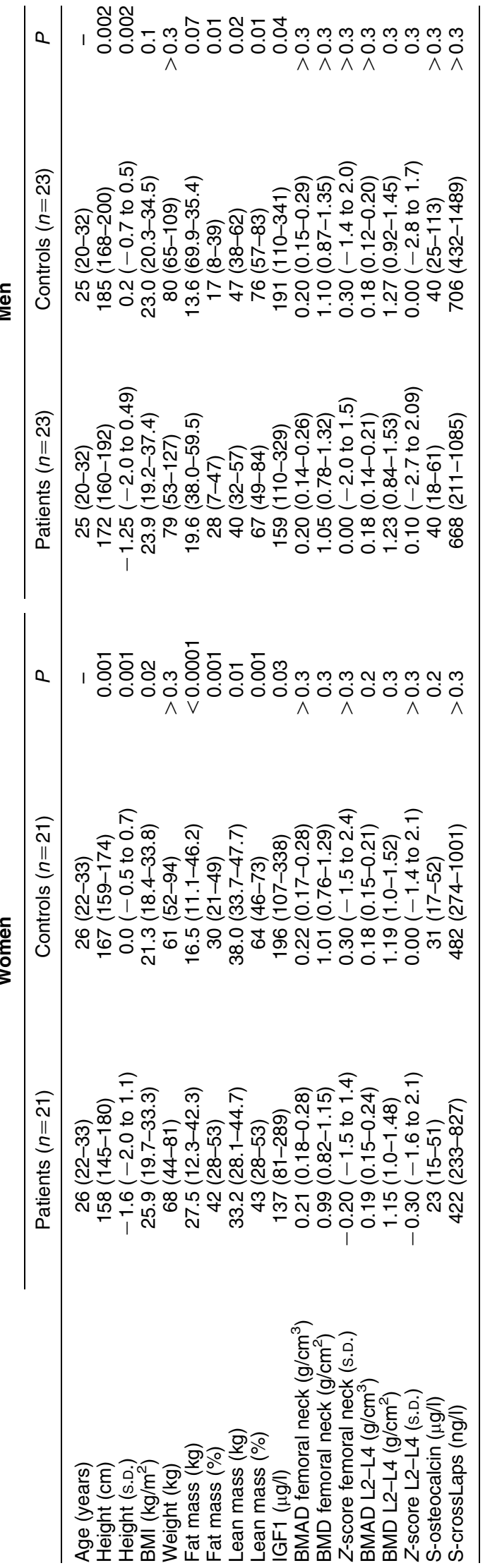


patients with normal testosterone secretion and thus isolated GHD $(n=12)$ were compared with those males with GHD and testosterone substitution $(n=10)$, the BMD measurements were without significant difference (data not shown).

No significant differences in the serum levels of osteocalcin and crossLaps (Table 2) or in calcium, albumin, phosphate or PTH levels were recorded between patients and controls in either gender (data not shown).

\section{History of previous fractures, daily calcium intake and physical exercise in 44 ALL patients in comparison with 44 matched population controls at baseline}

No significant difference in the number of previous fractures or present calcium intake was recorded in patients compared with controls of both genders $(P>0.3)$.

Further, there was no difference in the degree of physical exercise during leisure time between patients and controls of both genders $(P>0.3)$. However, during working time, both genders reported significantly higher degree of physical exercise compared with controls $(P=0.04)$.

\section{Correlations between disease-related factors to Z-scores and BMD among the 44 ALL patients at baseline}

The cumulative dose of MTX (p.o.) was negatively correlated to the Z-scores at L2-L4 $(r=-0.31$, $P=0.03$ ) (Fig. 2).

The cumulative dose of corticosteroids, level of serum IGF1, maximum GH response to GHRH-arginine, dose of CRT and time since diagnosis were without significant correlations to BMD or to Z-scores at L2-L4 and femoral neck (all; $P>0.3$ ) (data not shown).

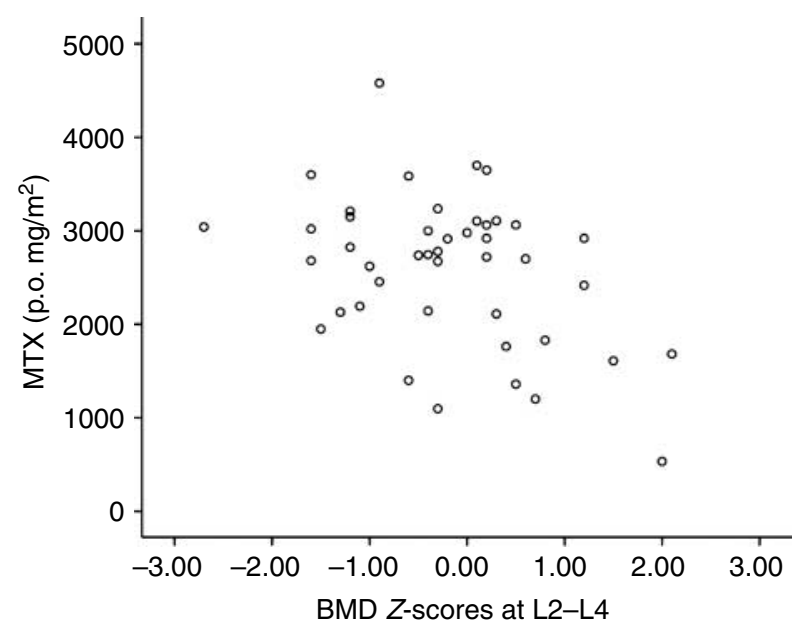

Figure 2 The cumulative dose of MTX p.o. was negatively correlated to the BMD $Z$-scores at L2-L4 $(r=-0.31, P=0.03)$ among the 44 ALL patients.

\section{Comparisons before and after 5 years of GH therapy in ALL patients and to the same matched population controls at baseline and after 5 years}

No significant difference in BMD, BMAD at any site or to the Z-Score at L2-L4 were recorded in former ALL patients of both genders before compared with those after 5 years of GH therapy, and with no differences in these measures in comparison to controls (Table 3). The Z-score at femoral neck decreased, but not significantly after 5 years of GH therapy $(-0.2$ to -0.6 ; Fig. 3A), and became significantly lower in ALL females, but not in males (Fig. 3A).

Serum crossLaps levels in the whole patient group significantly increased after GH therapy and became significantly higher than controls (Table 3). No significant change in serum levels of osteocalcin was recorded after 5 years and these levels remained similar to controls after 5 years. A significant increase in serum IGF1 levels were recorded from -2.5 to +0.05 s.D. $(P=0.03)$ and without differences in these levels compared with controls after 5 years. The IGF 1 levels in males increased from -2.8 to +0.05 s.D. and in females from -3.5 to -0.7 s.D. Serum levels of thyroid hormones, testosterone and $\mathrm{E}_{2}$ were without difference compared with controls after 5 years (data not shown) (all; $P>0.3$ ).

\section{Comparisons before and after 8 years without GH therapy in former $A L L$ patients and to the same matched population controls at baseline and after 8 years}

The serum IGF1 levels decreased further and became significantly lower after 8 years $(-2.0$ to -3.2 s.D.), corresponding to a decrease in serum IGF1 by $-30 \%$ $(-15$ to $-56 \%)$ (Table 4$)$.

Z-scores at femoral neck significantly decreased compared with baseline levels (0.0 to -0.5 s.D.; Fig. 3B) and became borderline significantly lower compared with controls after 8 years (Table 4). Analysis by gender in the untreated group was not possible due to the small number of women $(n=4)$.

Compared with controls, no significant difference in $\mathrm{BMD}$ and BMAD at L2-L4 was recorded at baseline, but after 8 years, BMD became significantly lower (Table 4). Z-scores at L2-L4 were borderline significantly lower at baseline, but after 8 years, these levels became significantly lower compared with controls (Table 4).

After 8 years, the serum levels of crossLaps and osteocalcin significantly decreased in patients, and these levels became significantly lower compared with controls after 8 years (Table 4). Levels of thyroid hormones, $\mathrm{E}_{2}$ and testosterone remained at similar levels as controls after 8 years (data not shown) (all; $P>0.3$ ). 


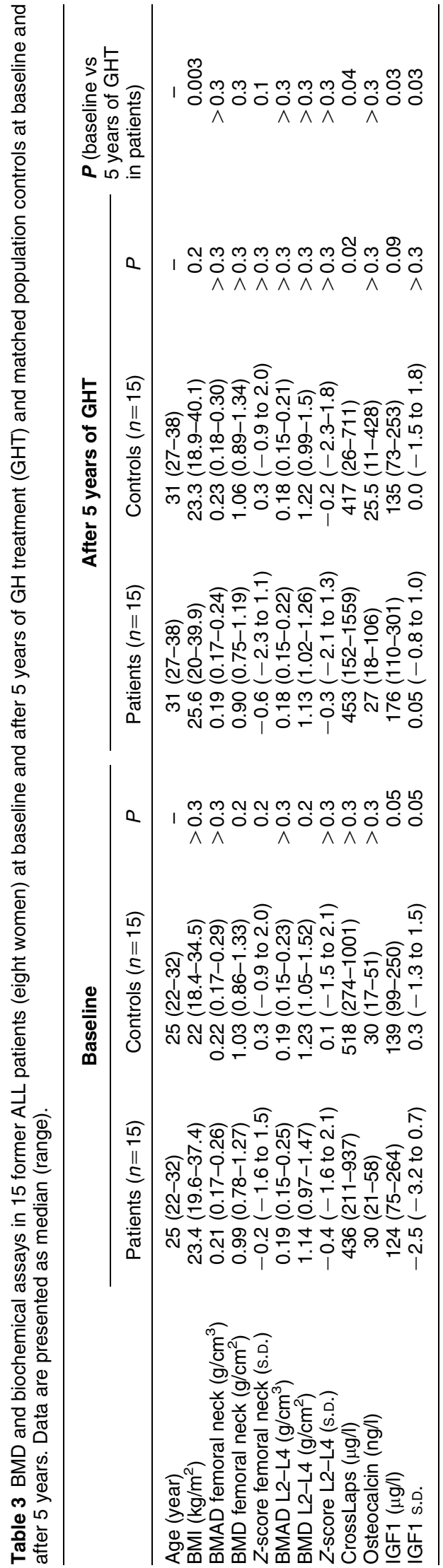

\section{Differences in the change of Z-scores between GH- and non-GH-treated patients}

The difference in the change of Z-scores between GH-treated and non-GH-treated patients was not significantly different $(P>0.3)$. The median net difference for the GH-treated versus non-GH-treated group for femoral Z-scores and for Z-scores at L2-L4 levels were -0.20 vs -0.25 and -0.10 vs -0.25 respectively.

\section{Discussion}

On average 20 years since diagnosis and CRT treatment, former ALL patients had, in comparison to matched population controls, no difference in BMD, BMAD or expressed as standardised Z-scores, at femoral neck or L2-L4. However, after an additional 8 years with GHD, Z-scores at femoral neck had significantly decreased from 0.0 to -0.5 S.D. and had together with Z-scores at L2-L4 become significantly lower compared with controls. In contrast, after 5 years of GH therapy, only female ALL patients had a significantly lower femoral neck Z-scores. This study is the first long-term prospective follow-up study of CRT-treated ALL patients, and patients were followed 20, 25 and 28 years since diagnosis. In addition, it is also the first to include proper controls and to control for variables as smoking, physical activity, calcium intake and all other hormones of importance for bone health.

The vast majority of the ALL patients were GH deficient $(91 \%)$ and the rest GH insufficient 20 years after diagnosis. However, their heights were only somewhat reduced $(-1.6$ in women and -1.25 in men), which means that they probably had partial GHD during puberty and adolescence, although treatments with dexamethasone and chemotherapeutic agents and the ALL disease itself could have halted growth. Recently (23), it was suggested that in patients with hypothalamic-pituitary injury following cranial irradiation, one cannot solely rely on the response to an ITT for the diagnosis of isolated GHD, as a few of these patients had normal spontaneous GH secretion. In this study, at baseline, we recorded a low ITT $(<3.0 \mu \mathrm{g} / \mathrm{l})$ response in three patients diagnosed with GHD, together with an IGF1 S.D. level of $>-2.0$ S.D. and a response to the GHRH-arginine test $>9 \mu \mathrm{g} / \mathrm{l}$. However, after 8 years, the non-GH-treated group had $<-2.0$ s.D. in serum IGF1, which clearly shows manifested GHD.

As the change from partial to more severely GHD is a continuum and is particularly evident after CRT, it is difficult to know when exactly GHD was manifested in the ALL patients (24). This was also illustrated by a further decrease in serum IGF1 after 8 years from -2.0 to -3.2 s.D. In parallel, a significant reduction in markers of bone turnover was also seen after 8 years, which coheres with the finding that patients with the most profound GHD also experienced the most depressed bone markers (25). This is in contrast to the 

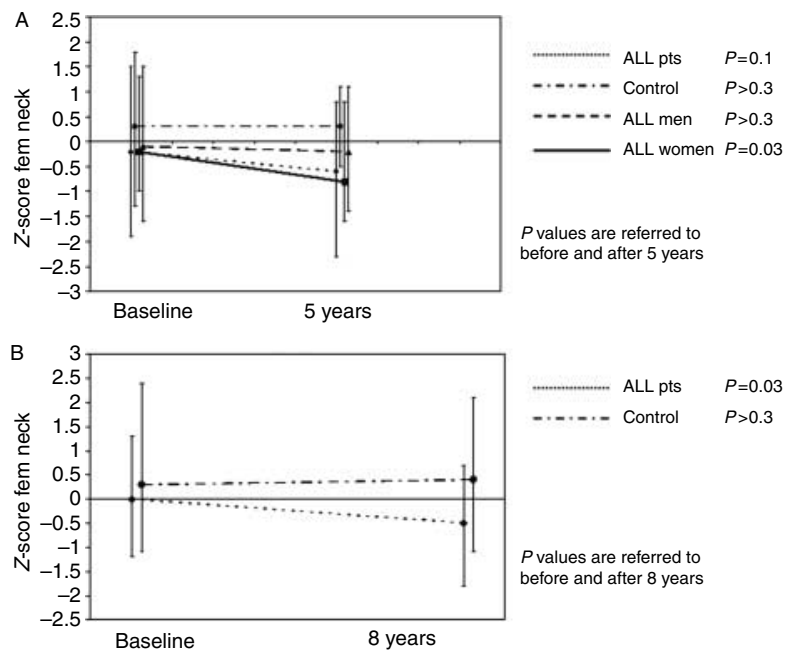

Figure 3 (A) BMD Z-score at femoral neck in 15 ALL patients before and after 5 years of GH therapy, in 15 matched population controls before and after 5 years, (B) in 13 ALL patients before and after 8 years without $\mathrm{GH}$ therapy and in 13 matched population controls before and after 8 years. Data are presented as median and range. $P$ values are referred to before and after 5 and 8 years respectively.

matched population controls where all BMD, Z-scores (Fig. 3A and B), bone markers and IGF1 measurements were stable or increased.

It has been shown that both GH and IGF1 stimulate osteoblasts resulting in bone formation, but also bone resorption (26). After GH therapy, several non-ALL studies report a temporary increase in osteocalcin with a peak after $1-3$ years followed by a decrease $(27,28)$. We recorded no difference in bone markers at baseline, which is in accordance with some previous studies on ALL patients $(14,15)$. After 5 years of GH therapy, however, crossLaps levels increased and osteocalcin levels remained unchanged, which coheres with increased bone resorption, but without concurrent increase in bone formation. In the GH-treated group, there was a non-significant decrease in the Z-scores at femoral neck. However, there was a gender difference, and in the ALL females, Z-scores at femoral neck were significantly reduced, but the serum IGF1 levels only increased to -0.7 s.D., which illustrates a low GH dose. In contrast, the ALL males had an increase to +0.05 S.D. in IGF1 and also received a better Z-score. There was, however, no significant net change in Z-scores between GH-treated and non-GH-treated patients, which means that the current $\mathrm{GH}$ regime did not show a clear positive effect on bone.

Hitherto, profound $\mathrm{CO}$ GHD patients have been GH treated during childhood and stopped GH therapy at final height. Studies in these patients have particularly been investigating if continuous GH therapy results in a progressive increase in BMD after epiphyseal closure and final height $(8,9,29-32)$ and whether stopping $\mathrm{GH}$ therapy causes a negative change in BMD. The longest follow-up in these patients is 2 years $(9,30-32)$, and

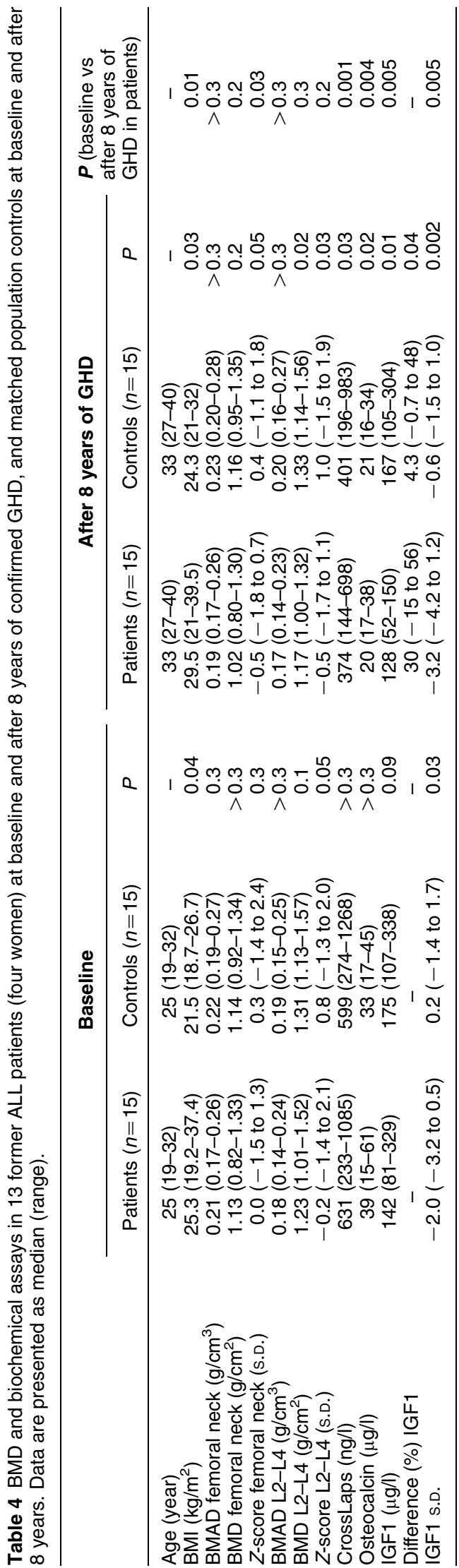

www.eje-online.org 
five studies included a control group of non-GH-treated patients who had been off GH therapy for 1 week to 5 years before enrolment $(8,9,30-32)$. BMD increased between 5 and $8 \%$ on GH therapy and between 1 and $5 \%$ in the non-GH-treated patients $(8,9,30,32)$, and in one study, no difference between groups was recorded (31). One problem with these studies is the carry-over effect of previous GH therapy on BMD that will last for 1-2 years after stopping GH therapy (9). Furthermore, higher $\mathrm{GH}$ doses were used and some even used paediatric doses $(9,30)$, and particularly females needed the higher doses (32), as they are less sensitive to standard GH doses $(32,33)$. GH-deficient ALL patients are, however, different from patients in the above-mentioned studies, as most of the ALL patients are GH naïve and have changed from partial GHD to insufficient and more severely GHD later in life. Thus, there are several reasons for the failed net effect of the present GH therapy: i) no recent GH therapy, ii) too low GH dose (females) and iii) a start of GH therapy at 25 years of age might be somewhat late to improve BMD and PBM. However, the Z-scores only dropped to -0.6 S.D., but it occurred when PBM is attained and interference with PBM is perhaps the most important determinant of lifelong skeletal health.

Our study has some limitations that may potentially impact the findings. We did not conduct a randomised placebo-controlled study, and the population we studied was small and the follow-up was different between the two groups. However, the baseline characteristics and treatment modalities were very similar and without substantial difference in treated or non-treated patients (Table 1). Furthermore, the non-GH-treated group was observed for 8 years, which in fact may result in a worsening of BMD in comparison with the possible improvement that could be seen within 5 years of $\mathrm{GH}$ therapy. At the start of the this study, the intention was to treat a subgroup of the ALL patients as none hitherto has done so and also to give a physiological rather low GH dose aiming at a serum IGF1 level of \pm 0 s.D. The reason for this precaution was an ongoing discussion on the risk of second neoplasms in this patient population. At present, however, there seem to be a particularly high risk for meningiomas, which seem to be connected to previous CRT (34).

The unexpected breakdown of the DXA machine had probably no impact on the present results as the $\mathrm{CV} \%$ between machines was very low $(\mathrm{CV} \% 0.7)$ and that all patients together with their controls were scanned with the same DXA machine at baseline and after 5 and 8 years respectively.

A further causative factor for low BMD is reduced physical activity, shown among ALL children (35). However, we have previously shown that adult ALL patients experience no difference in the degree of physical exercise during spare time, but during working time, they reported significantly more physical exercise compared with their matched controls (5). This study showed no change in these activities after an additional 5 and 8 years respectively.

Another new finding was the significant association between a low dose of MTX p.o. $\left(2700 \mathrm{mg} / \mathrm{m}^{2}\right)$ and the Z-score at L2-L4, as previously only high-dose MTX $\left(>40000 \mathrm{mg} / \mathrm{m}^{2}\right)$ has been correlated to low BMD (18). Experimental studies show that MTX strongly inhibits osteoblast proliferation and causes a decrease in bone formation (36). The interpretation of the present results, 20 years after ALL diagnosis, is hardly an ongoing MTX effect but mirrors a previous arrest of bone formation during periods of MTX therapy.

In conclusion, on average 20 years after ALL treatment with $24 \mathrm{~Gy}$ and a low dose of MTX, normal BMD and Z-scores were recorded in GH-deficient ALL patients. Thereafter, Z-scores at femoral neck decreased significantly during the following 8 years, which means that if Z-scores continue to decrease, there is a premature risk for osteoporosis. The present GH therapy regime did not show a clear positive effect on bone formation. Besides GHD, yet unknown factors have also to be considered. Whether higher $\mathrm{GH}$ doses, particularly in women, will improve Z-scores needs further investigation.

\section{Declaration of interest}

E M Erfurth is a member of Eli Lilly Advisory Board. The authors have nothing to disclose.

\section{Funding}

This work was supported by the Swedish Children's Cancer Foundation and the Medical Faculty, Lund University, Sweden.

\section{References}

1 Oeffinger KC, Eshelman DA, Tomlinson GE, Tolle M \& Schneider G. Providing primary care for long-term survivors of childhood acute lymphoblastic leukemia. Journal of Family Practice 200049 1133-1146.

2 Robson $\mathrm{H}$, Anderson $\mathrm{E}$, Eden $\mathrm{O}$, Isaksson $\mathrm{O}$ \& Shalet $\mathrm{S}$. Chemotherapeutic agents used in the treatment of childhood malignancies have a direct effects on growth plate chondrocyte proliferation. Journal of Endocrinology $1998 \quad 157 \quad 225-235$. (doi:10.1677/joe.0.1570225)

3 Sala A \& Barr R. Osteopenia and cancer in children and adolescents. Cancer 2007109 1420-1431. (doi:10.1002/cncr.22546)

4 Brennan BMD, Rahim A \& Mackie EM. Growth hormone status in adults treated for acute lymphoblastic leukaemia in childhood. Clinical Endocrinology 199848 777-783. (doi:10.1046/j.13652265.1998.00438.x)

5 Link K, Moëll C, Garwicz S, Cavallinj-Ståhl E, Björk J, Thilén U, Ahrén B \& Erfurth EM. Growth hormone deficiency predicts cardiovascular risk in young adults treated for acute lymphoblastic leukaemia in childhood. Journal of Clinical Endocrinology and Metabolism 200489 5005-5012. (doi:10.1210/jc.2004-0126)

6 Kaufman JM, Taelman P, Vermeulen A \& Vandeweghe M. Bone mineral status in growth hormone-deficient males with isolated and multiple pituitary deficiencies of childhood onset. Journal of Clinical Endocrinology and Metabolism 199274 118-123. (doi:10. 1210/jc.74.1.118) 
7 Saggese G, Baroncelli B, Bertelloni S \& Barsanti S. The effect of long-term growth hormone $(\mathrm{GH})$ treatment on bone mineral density in children with GH deficiency. Role of GH in the attainment of peak bone mass. Journal of Clinical Endocrinology and Metabolism 199681 3077-3088. (doi:10.1210/jc.81.8.3077)

8 Drake WM, Caroll P, Maher K, Metcalfe A, Camacho-Hübner C, Shaw N, Dunger T, Cheetham T, Savage M \& Monson J. The effect of cessation of growth hormone $(\mathrm{GH})$ therapy on bone mineral accretion in GH-deficient adolescents at the completion of linear growth. Journal of Clinical Endocrinology and Metabolism $2003 \mathbf{8 8}$ 1658-1663. (doi:10.1210/jc.2002-021541)

9 Shalet S, Shavrikova E, Cromer M, Child C, Keller E, Zapletalova J, Moshang T, Blum W, Chipman J, Quigley C \& Attanasio A. Effects of growth hormone $(\mathrm{GH})$ treatment on bone in postpubertal GH-deficient patients: a 2-years randomized, controlled, doseranging study. Journal of Clinical Endocrinology and Metabolism 200388 4124-4129. (doi:10.1210/jc.2003-030126)

10 Katzman D, Bachrach L, Carter D \& Marcus R. Clinical and anthropometric correlates of bone mineral acquisition in healthy adolescent girls. Journal of Clinical Endocrinology and Metabolism 199173 1332-1339. (doi:10.1210/jcem-73-6-1332)

11 Gilsanz V, Carlsson M, Roe T \& Ortega J. Osteoporosis after cranial irradiation for acute lymphoblastic leukemia. Journal of Pediatrics 1990117 238-244. (doi:10.1016/S0022-3476(05)80536-0)

12 Nussey S, Hyer S, Brada M \& Leiper AD. Bone mineralization after treatment of growth hormone deficiency in survivors of childhood malignancy. Acta Paediatrica 1994399 9-14. (doi:10.1111/ j.1651-2227.1994.tb13276.x)

13 Nysom K, Holm K, Michaelsen K, Hertz H, Müller J \& Mölgaard C. Bone mass after treatment for acute lymphoblastic leukaemia in childhood. Journal of Clinical Oncology 199812 3752-3760.

14 Hoorweg-Nijman J, Kardos G, Roost J, van Dijk H, Netelenbost C, Popp-Snijders C, de Ridder C \& Delemarre-van de Waal H. Bone mineral density and markers of bone turnover in young adult survivors of childhood lymphoblastic leukemia. Clinical Endocrinology 199950 237-244. (doi:10.1046/j.1365-2265. 1999.00654.x)

15 Brennan BMD, Rahim A, Adams J, Eden O \& Shalet S. Reduced bone mineral density in young adults following cure of acute lymphoblastic leukaemia in childhood. British Journal of Cancer 199979 1859-1863. (doi:10.1038/sj.bjc.6690296)

16 Thomas I, Donohue J, Ness K, Dengel D, Baker K \& Gurney J. Bone mineral density in young adult survivors of acute lymphoblastic leukaemia. Cancer 2008113 3248-3256. (doi:10.1002/cncr. 23912)

17 Jarfelt M, Fors H, Lannering B \& Bjarnason R. Bone mineral density and bone turnover in young adult survivors of childhood acute lymphoblastic leukaemia. European Journal of Endocrinology 2006154 303-309. (doi:10.1530/eje.1.02092)

18 Mandel K, Atkinson S, Barr R \& Pencharz P. Skeletal morbidity in childhood acute lymphoblastic leukaemia. Journal of Clinical Oncology 200422 1215-1221. (doi:10.1200/JCO.2004.04.199)

19 Lewiecki EM, Watts NB, McClung MR, Petak S, Bachrach L, Shepherd J \& Downs R. Official positions of the International Society for Clinical Densitometry. Journal of Clinical Endocrinology and Metabolism 2004 89 3651-3655. (doi:10.1210/jc.2004-0124)

20 Wilhelmsen L, Tibblin G \& Aurell M. Physical fitness and risk of myocardial infarction. Advances in Cardiology $1976 \mathbf{1 8} 217-230$.

21 Ghigo E, Aimaretti G \& Arvat E. Growth hormone-releasing diagnosis of growth hormone deficiency in adults. Endocrine 2001 15 29-38. (doi:10.1385/ENDO:15:1:029)

22 Corneli G, Di Somma C, Baldelli B, Rovere S, Gasco V, Croce C, Grottoli S, Maccario M, Colao A, Lombardi G, Ghigo E \& Camanni F. The cut-off limits of the GH response to GH-releasing hormonearginine test related to body mass index. European Journal of Endocrinology 2005153 257-264. (doi:10.1530/eje.1.01967)

23 Darzy K, Thorner M \& Shalet S. Cranially irradiated adult cancer survivors may have normal spontaneous GH secretion in the presence of discordant peak GH response to stimulation tests (compensated GH deficiency). Clinical Endocrinology $2009 \mathbf{7 0}$ 287-293. (doi:10.1111/j.1365-2265.2008.03359.x)

24 Clayton P \& Shalet S. Dose dependency of time of onset of radiation-induced growth hormone deficiency. Journal of Pediatric 1991118 226-228. (doi:10.1016/S0022-3476(05)80487-1)

25 Colao A, Di Somma C, Pivonello R, Aimaretti G, Cerbone G, Faggiano A, Corneli G, Ghigo E \& Lombardi G. Bone loss is correlated to severity of growth hormone deficiency in adult patients with hypopituitarism. Journal of Clinical Endocrinology and Metabolism 1999 84 1919-1924. (doi:10.1210/jc.84.6.1919)

26 Ohlsson C, Bengtsson BÅ, Isaksson O, Andreassen T \& Slootweg M. Growth hormone and bone. Endocrine Reviews 199819 55-79. (doi:10.1210/er.19.1.55)

27 Vandeweghe M, Taelman P \& Kaufman J. Short end long-term effects of growth hormone treatment on bone turnover and bone mineral content in adult growth hormone-deficient males. Clinical Endocrinology 199339 409-415. (doi:10.1111/j.1365-2265. 1993.tb02387.x)

28 Bravenboer N, Holzmann P, Ter Maaten J, Stuurman L, Roos J \& Lips P. Effect of long-term growth hormone treatment on bone mass and bone metabolism in growth hormone-deficient men. Journal of Bone and Mineral Research 200520 1778-1784. (doi:10.1359/JBMR.050613)

29 Holmes S, Whitehouse R, Economou G, O'Halloran D, Adams J \& Shalet S. Further increase in forearm cortical bone mineral content after discontinuation of growth hormone replacement. Clinical Endocrinology 199542 3-7. (doi:10.1111/j.1365-2265. 1995.tb02591.x)

30 Underwood L, Attie K \& Baptista J. Growth hormone (GH) dose-response in young adults with childhood-onset $\mathrm{GH}$ deficiency: a two-year, multicenter, multiple-dose, placebo-controlled study. Journal of Clinical Endocrinology and Metabolism $2003 \mathbf{8 8}$ 5273-5280. (doi:10.1210/jc.2003-030204)

31 Mauras N, Pescowitz O, Allada V, Messig M, Wajnrajch M \& Lippe B. Limited efficacy of growth hormone (GH) during transition of GH-deficient patients from adolescence to adulthood: a phase III multicenter, doubled-blind, randomized two-year trial. Journal of Clinical Endocrinology and Metabolism 200590 3946-3955. (doi:10.1210/jc.2005-0208)

32 Conway G, Szarras-Czapnik M, Racz K, Keller A, Chanson P, Tauber M \& Zacharin M. Treatment for 24 months with recombinant human $\mathrm{GH}$ has a beneficial effect on bone mineral density in young adults with childhood-onset GH deficiency. European Journal of Endocrinology 2009160 899-907. (doi:10. 1530/EJE-08-0436)

33 Johansson A, Éden Engström B, Ljunghall S, Karlsson A \& Burman P. Gender differences in the effects of long term growth hormone $(\mathrm{GH})$ treatment on bone in adults with $\mathrm{GH}$ deficiency. Journal of Clinical Endocrinology and Metabolism $1999 \mathbf{8 4}$ 2002-2007. (doi:10.1210/jc.84.6.2002)

34 Ergun-Longmire B, Mertens A, Mitby P, Qin J, Heller G, Shi W, Yasui Y, Robison L \& Sklar C. Growth hormone treatment and risk of second neoplasm in the childhood cancer survivor. Journal of Clinical Endocrinology and Metabolism 200691 3494-3498. (doi:10.1210/jc.2006-0656)

35 Warner J, Evans W, Webb D, Bell W \& Gregory J. Relative osteopenia after treatment for acute lymphoblastic leukaemia. Pediatric Research 199945 544-551. (doi:10.1203/00006450199904010-00014)

36 Wheeler D, Vander Griend R, Wronski T, Miller G, Keith E \& Graves J. The short- and long-term effects of methotrexate on the rat skeleton. Bone 199516 215-221. (doi:10.1016/87563282(94)00032-U)

Received 16 February 2011

Accepted 4 March 2011 